\title{
Attention Bias in Children of Patients with Panic Disorder
}

\author{
Silvia Schneider ${ }^{a}$ Suzan Unnewehr ${ }^{c}$ Tina In-Albon ${ }^{a}$ Jürgen Margraf ${ }^{b}$ \\ ${ }^{\mathrm{a} C l i n i c a l}$ Child and Adolescent Psychology, and ${ }^{\mathrm{b}} \mathrm{Clinical}$ Psychology and Psychotherapy, University of Basel, \\ Basel, Switzerland; 'Psychotherapeutische Praxis, Berlin, Germany
}

\section{Key Words}

Attentional bias $\cdot$ Childhood anxiety $\cdot$ Panic disorder .

Emotional Stroop task

\begin{abstract}
Cognitive models of panic disorder have emphasized the role of cognitive distortions in the maintenance of this disorder. Several studies have produced results consistent with this hypothesis, but it is still unclear whether cognitive biases precede anxiety disorders or whether they are a consequence of the disorder. In the present study, we compared children of individuals with panic disorder, children of individuals with animal phobia, and children of normal controls with respect to attentional bias with an emotional Stroop task, which included three types of words: panic-relevant, animal phobia-relevant, and neutral words. Our results revealed that children of panic patients did not show an attentional bias for panic-relevant stimuli. Results will be discussed in the context of theoretical models explaining the etiological factor of cognitive biases for the development of anxiety disorders.

Copyright $\odot 2008$ S. Karger AG, Basel
\end{abstract}

\section{Introduction}

Over the past two decades, many clinical researchers have been interested in elucidating the cognitive processes underlying panic disorder [1]. Indeed, influential psychological models of anxiety disorders have postulated that cognitive processes are crucial for the maintenance of this disorder [2-5]. Studies investigating cognitive biases provide convincing empirical support for the notion that panic disorder is associated with various cognitive biases, such as an attentional bias. In investigating the attentional bias, an emotional Stroop task can be applied. In the procedure of the emotional Stroop task, the participant is required to name the color of threat-related words and neutral words as quickly as possible, while ignoring the meaning of the words. Delays in processing the color of the words ('Stroop interference effect') occur when the meaning of the word attracts the subjects' attention, despite their efforts to attend to the ink of the word. Consequently, higher interference scores reflect an increased attentional bias, which is defined as the delay in color naming of threatening words compared to neutral words.

With respect to attentional bias in individuals with panic disorder, the emotional Stroop task has been used in several studies [6-9]. The results of these studies indicate that panic patients demonstrate Stroop interference effects for panic-relevant words, especially words referring to various kinds of catastrophic consequences, but also words referring to fear and body sensations [9].

Overall, these results support an association between attentional bias and panic disorder. However, the design of these studies cannot address the question whether this bias precedes the disorder and contributes to its etiology or whether it is a consequence of the disorder and mainly contributes to its maintenance. A possibility to examine this question is to study people longitudinally who are at

\section{KARGER \\ Fax +41613061234 \\ E-Mail karger@karger.ch}

www.karger.com
(C) 2008 S. Karger AG, Basel

0254-4962/08/0413-0179\$24.50/0

Accessible online at:

www.karger.com/psp
Silvia Schneider, $\mathrm{PhD}$

Institut für Psychologie, Abteilung Klinische Kinder- und Jugendpsychologie

Universität Basel, Missionsstrasse 60/62

$\mathrm{CH}-4055$ Basel (Switzerland)

Tel. +41 6126706 50, Fax +416126703 39, E-Mail silvia.schneider@unibas.ch 
risk for developing panic disorder. Especially, because several family studies have established that panic disorder runs in families [10-12], Biederman et al. [12] concluded that parental panic disorder, regardless of comorbidity with major depression, was associated with an increased risk for panic disorder and agoraphobia in the offspring. Furthermore, findings from behavioral genetic studies point to the genetic influence on anxiety in childhood, which accounts for around one third of the variance in most cases [13]. Thus, offspring of patients with panic disorder are a group at risk for developing the disorder.

Stroop studies with clinical and nonclinical anxious children have so far provided inconsistent results. While an interference effect was found in clinical anxious children [14-17], several other studies could not find an attentional bias [18-20]. Stroop studies with risk groups for psychopathology have also presented conflicting results. Several studies suggest that panic attacks are associated with an increased likelihood of panic disorder and of a wide range of mental disorders [21, 22]. Ehlers et al. [6] investigated nonclinical individuals with panic attacks and demonstrated a similar Stroop interference effect regarding panic-relevant words, as shown by individuals with panic disorder. Another study investigated individuals with high versus low anxiety sensitivity with a Stroop test [23]. High-anxiety-sensitive individuals showed significantly greater interference in physical threat words than low-anxiety-sensitive individuals. However, the studies of Ehlers et al. [6] and Stewart et al. [23] were conducted with adults. Another study was conducted with adolescents, who had been classified as behaviorally inhibited or uninhibited in their 2nd year of life and were therefore supposed to be at risk for the development of anxiety disorders in adulthood [24]. Although the mean color-naming times for the behaviorally inhibited and uninhibited adolescents did not differ, Schwartz et al. [24] found that a greater percentage of extremely long color-naming latencies occurred among threat words in the behaviorally inhibited group compared to the uninhibited group. In contrast, positive words accounted for a greater percentage of extreme values among uninhibited children. Kagan et al. [25] compared 7-year-olds who had been classified as either being high reactive (frequent fretting and crying) or low reactive (infrequent motor activity and infrequent fretting and crying) in infancy. No different patterns of color-naming latencies were found to differentiate anxious from nonanxious or high from low reactive children.

Taken together, the results demonstrated that the attentional bias is already evident in persons identified as being at risk for the development of the disorder and does not appear to be limited to patients with clinically diagnosed panic disorder.

The present study examined the presence of an attentional bias in children of parents with panic disorder who did not exhibit the disorder or panic attacks themselves. We hypothesized that similar to nonclinical panickers such as high-anxiety-sensitive individuals and behaviorally inhibited adolescents, these children would demonstrate the attentional bias when presented with panic-relevant words. To test for specificity in attention bias we compared three categories of words: panic-relevant, spider phobia-relevant, and neutral words. Family studies suggest that specific phobia is a highly familial disorder $[26,27]$. Within specific phobias, animal phobia and especially the fear of insects is highly prevalent [28]; therefore, spider phobia-relevant words were used in this investigation. We predicted that (a) children of individuals with panic disorder would demonstrate a higher interference score with panic-relevant words than with phobiarelevant words and (b) children of individuals with panic disorder would show a higher interference score with panic-relevant stimuli than would children of individuals with animal phobias and children of healthy controls.

\section{Materials and Methods}

\section{Participants}

Patients with panic disorder of an Anxiety Disorders Outpatient Clinic, with children between the ages of $8-15$ years, were asked to participate in this investigation. Parents with animal phobia and healthy control parents with children were recruited via newspaper advertisement, were paid DEM 50 (about USD 30) and were given information about treatment possibilities. The sample consisted of 27 children of parents with panic disorder and agoraphobia (CPAN), 19 children of parents with animal phobias (CPHOB), and 29 children of parents without any psychiatric disorder (CCON). All parents provided informed consent and had obtained the consent of their children to participate. The children received a small, age-appropriate gift for their participation.

\section{Parents}

The CPAN and CPHOB groups consisted at least of one parent with the target diagnosis, while in the CCON group neither parent was allowed to have had any history of psychiatric disorder. Furthermore, in the CPAN group, children of parents with panic disorder with a history of animal phobia were excluded from the study. Similarly, in the CPHOB group, children of parents with a history of panic disorder were excluded. The parents in the CPHOB group were a mixed group of individuals with animal phobia such as $53 \%$ spider phobia, $27 \%$ dog phobia, $13 \%$ mouse 
Table 1. Means with standard deviations in parentheses for characteristics of parents and children

\begin{tabular}{|c|c|c|c|c|}
\hline & \multicolumn{3}{|l|}{ Groups } & \multirow[t]{2}{*}{$\mathrm{p}$} \\
\hline & CPAN & СРНОВ & CCON & \\
\hline Parents & $\mathrm{n}=17$ & $\mathrm{n}=15$ & $\mathrm{n}=23$ & \\
\hline Age, years & $38.12(4.40)$ & $36.60(5.14)$ & $37.13(5.25)$ & n.s. \\
\hline Severity of target diagnosis (scale $0-8$ ) & $5.41(1.77)$ & $3.73(0.80)$ & - & $<0.01$ \\
\hline Duration of target diagnosis, years & $7.33(6.90)$ & $24.10(11.37)$ & - & $<0.01$ \\
\hline Children & $\mathrm{n}=27$ & $\mathrm{n}=19$ & $\mathrm{n}=29$ & \\
\hline Age, years & $11.00(1.90)$ & $11.26(1.82)$ & $10.83(1.77)$ & \\
\hline Female, $\%$ & $48(n=13)$ & $74(\mathrm{n}=14)$ & $48(n=14)$ & \\
\hline STAIC-T (scale 20-60) & $35.60(7.53)$ & $36.16(5.32)$ & $31.86(5.81)$ & \\
\hline STAIC-S (scale 20-60) & $32.07(6.45)$ & $33.89(3.94)$ & $30.21(4.10)$ & \\
\hline Panic symptom list (scale $0-57$ ) & $4.56(5.85)$ & $5.32(3.02)$ & $2.90(3.03)$ & \\
\hline
\end{tabular}

STAIC-T = Trait subscale of the State-Trait Anxiety Inventory for Children; STAIC-S = state subscale of the State-Trait Anxiety Inventory for Children.

phobia, and $7 \%$ bird phobia. Parents were diagnosed using a structured interview (DIPS) [29], an adapted German version of the ADIS-IV-L [30] for the assessment of mental disorders according to DSM-IV [31]. The DIPS has demonstrated good validity and reliability for anxiety disorders (kappa $=0.64)$, for panic disorders (kappa $=0.69$ ) and other axis I disorders [32]. Characteristics of the participating parents are presented in table 1 . Since we included several children of one parent, the number of parents is less than the number of children.

In more than $80 \%$ of the cases, the mother was the target parent. The three groups did not differ significantly on this factor (female: CPAN 88\%, CPHOB 93\%, CCON 83\%). The parent groups were comparable with respect to age $\left(\mathrm{F}_{2,52}=0.39\right.$, n.s. $)$ and sex $\left[\chi^{2}{ }_{(2)}=96\right.$, n.s. $]$. The two clinical groups (CPAN and CPOB) differed significantly on severity and duration of target diagnoses (severity: $\mathrm{t}_{22.85}=3.52, \mathrm{p}<0.01$; duration: $\mathrm{t}_{23}=-4.60, \mathrm{p}<0.001$ ). Because most animal phobias have their onset in childhood or adolescence, the duration of the disorder was significantly longer in the parents with animal phobia than in the parents with panic disorder. Furthermore, the disorder was rated as significantly less severe in the former than in the latter group. No differences were found in marital status, education or current employment between the three parent samples.

\section{Children}

Children were between 8 and 15 years of age. The sample included 41 girls and 34 boys, with a mean age of 11.03 years $(\mathrm{SD}=$ 1.83). To investigate children before experiencing any panic attacks, we only included children younger than 16 years. Data indicate that panic attacks are very rare before adolescence [33]. Since the children needed reading abilities, we excluded children younger than 8 years of age. A total of 27 children of 17 parents with panic disorder, 19 children of 15 parents with animal phobia, and 29 children of 23 healthy control parents participated in this study. The groups were matched in age $\left(F_{2,72}=0.32\right.$, n.s. $)$ and comparable in sex $\left[\chi_{(2)}^{2}=0.23\right.$, n.s. $]$.

Attention Bias in Children of

Panic-Disordered Patients
Children completed the German translation of the trait and state forms of the State-Trait Anxiety Inventory for Children [34, 35], a panic symptom list for children including a measure of frequency of panic symptoms, a modified version of the panic symptom list for adults developed by Margraf [36], and ratings of state anxiety and state excitement, on a 5-point scale. We measured excitement because the children in the three groups might differ in the way they labeled arousal. All ratings were based on self-report measurements. Demographic and clinical characteristics of the participants are reported in table 1. A MANOVA performed on the trait and state forms of the State-Trait Anxiety Inventory for Children and the panic symptom list did not reveal a significant group effect $\left(\mathrm{F}_{6,138}=1.34\right.$, n.s. $)$.

To establish whether children met current or past criteria for DSM-IV mental disorders, we conducted separate structured interviews with children and their parents. We used the KinderDIPS [37], which assesses all anxiety disorders of childhood and adolescence, depression, attention deficit hyperactivity disorder, oppositional defiant disorder, enuresis, and encopresis. Previous studies with the Kinder-DIPS indicated that this instrument has a good validity and reliability (kappa $=0.50-0.89$ ) [38]. Children of parents with either animal phobias or panic disorder had significantly more anxiety disorders than the children of the control group. Children of the $\mathrm{CPHOB}$ group more frequently reported animal phobia (spider: $\mathrm{CPAN}=15 \%, \mathrm{CPHOB}=32 \%, \mathrm{CCON}=0 \%$; dog: $\mathrm{CPAN}=0 \%, \mathrm{CPHOB}=5 \%, \mathrm{CCON}=7 \%$; other animals: $\mathrm{CPAN}=7 \%, \mathrm{CPHOB}=0 \%, \mathrm{CCON}=0 \%$ ), whereas children in the CPAN group more frequently reported anxiety disorders other than specific phobias (e.g. separation anxiety disorder, generalized anxiety disorder, social anxiety disorder). These results are reported in detail in Unnewehr et al. [39].

\section{Stimulus Materials}

Three categories of words were used: 12 panic-relevant words, 12 spider-phobia-relevant words, and 12 neutral words (the list can be requested from the authors). As emphasized by Vasey [40], it was considered to select age-appropriate words. A pilot test was 
Table 2. Color-naming times (in seconds) for single cards and Stroop interference index

\begin{tabular}{lrrr}
\hline \multicolumn{4}{l}{ Groups } \\
\cline { 2 - 4 } & CPAN $(\mathrm{n}=27)$ & CPHOB $(\mathrm{n}=19)$ & CCON $(\mathrm{n}=29)$ \\
\hline Single cards & & & \\
$\quad$ Color words & $102.55(30.14)$ & $104.57(25.93)$ & $111.96(33.11)$ \\
Panic words & $87.39(29.27)$ & $92.36(18.54)$ & $97.80(26.56)$ \\
Phobia words & $86.05(29.41)$ & $104.66(40.53)$ & $97.91(29.56)$ \\
$\quad$ Control words & $83.77(28.86)$ & $94.34(36.07)$ & $96.29(27.21)$ \\
Interference index & & & \\
$\quad$ Panic & $3.62(11.47)$ & $-1.98(26.23)$ & $1.52(10.77)$ \\
Phobia & $2.28(14.29)$ & $10.32(21.05)$ & $1.63(12.61)$ \\
\hline
\end{tabular}

Figures are means with standard deviations in parentheses. conducted with 46 children (26 girls) to select appropriate words that could be read and understood by children between the ages of 8 and 14 . We examined 20 words per category which were derived by translating words used in earlier studies of attentional bias in panic and spider-phobic patients and by searching age-appropriate synonyms of these. The selected words per category were matched for number of letters, syllables, nouns, verbs, and adjectives. The selected panic-relevant and spider-phobia-relevant words reached significantly higher threat ratings compared to the neutral words (panic vs. neutral: $t_{45}=15.02$, $\mathrm{p}<0.001$; phobia vs. neutral: $\mathrm{t}_{45}=11.58, \mathrm{p}<0.001$ ), whereas the familiarity of the words from the different categories was comparable.

The selected words were printed on cards in red, blue, black, or green ink $(21 \times 30 \mathrm{~cm})$. Each card contained a set of 12 different words. This set of words was repeated 8 times in random order. A card contained 8 columns of 12 words giving a total of 96 words with the restriction that the same color did not occur twice in a row. Kindt et al. [19] found an attentional bias regardless of the format (card format or single-word presentation) used. Furthermore, Waters et al. [41] showed that the card format could better discriminate clinical from nonclinical groups.

\section{Procedure}

Each participant was tested individually. After completing questionnaires and the diagnostic interview, the children were asked to name the colors of the ink in which the words were written as quickly as possible while not reading the word. After a practice run with a card containing neutral words, the standard Stroop card (color words) was given. The panic, phobia, and neutral cards were then presented in balanced order. The speed of reading was timed to $0.10 \mathrm{~s}$ with a stopwatch. Importantly, the experimenter was blinded to the risk status of the child. Before and after the color-naming tasks, state anxiety and state excitement ratings were collected.

\section{Emotional Stroop Test}

To control for age-related reading times in our sample $(r=$ -0.66), we computed interference index scores (i.e. difference scores) as dependent variables. The interference index estimates the extra processing time associated with the emotional content of the experimental words compared with the processing time associated with the neutral words, after controlling for intersubject differences in color-naming speed [42]. Two interference index scores (panic and spider phobia) were calculated for each subject by subtracting the mean latency for the neutral words from the mean latency for the panic and spider phobia words, respectively. Higher positive scores on these interference indices indicate relatively greater degrees of selective processing of panic and spider phobia cues, respectively.

A 2-way repeated-measures ANOVA was performed with one between-subject factor (group: CPAN, CPHOB; CCON), and one repeated-measure factor (interference type: panic, phobia). Significant main effects and interactions were followed by separate one-way ANOVAs and by the post hoc Student-Newman-Keuls test or paired comparisons based on separate variance $t$ tests.

\section{State Anxiety and State Excitement}

A 2-way repeated-measures MANOVA with the between-subject factor 'group' (CPAN, CPHOB; CCON) and repeated-measure factor 'time' (before, after) was performed on the subjective measures state anxiety and state excitement. Subsequently, paired comparisons based on separate variance t tests (before vs. after) were computed for state anxiety and state excitement separately.

Subject observations were not completely independent in that more than one child from the same family was tested ( 2 children per family: $\mathrm{CPAN}=6, \mathrm{CPHOB}=2, \mathrm{CCON}=6 ; 3$ children per family: $\mathrm{CPAN}=2, \mathrm{CPHOB}=1 ; \mathrm{CCON}=0)$. An additional analysis controlled for this factor: only one child per family was randomly selected, and all analyses were repeated with the smaller sample $(\mathrm{CPAN}=17, \mathrm{CPHOB}=15, \mathrm{CCON}=23$ children $)$. No differences between the two analyses were observed. Therefore, only results for the total sample will be reported.

\section{Results}

\section{Emotional Stroop Test}

The mean color-naming latencies and the interfering indices are reported in table 2 .

The $3 \times 2$ ANOVA performed on the interference index score revealed a marginally significant group $\times$ interference type interaction $\left(\mathrm{F}_{2,72}=3.04, \mathrm{p}=0.054\right)$, while 
Table 3. Reactions in anxiety rating and excitement rating to the Stroop task and detailed results of the statistical analyses

\begin{tabular}{|c|c|c|c|}
\hline & \multicolumn{3}{|l|}{ Groups } \\
\hline & CPAN $(\mathrm{n}=27)$ & СРHOB $(\mathrm{n}=19)$ & $\operatorname{CCON}(n=29)$ \\
\hline \multicolumn{4}{|l|}{ Before the task } \\
\hline Anxiety rating & $0.33(0.83)$ & $0.21(0.54)$ & $0.17(0.47)$ \\
\hline Excitement rating & $0.67(0.92)$ & $0.90(0.94)$ & $0.38(0.56)$ \\
\hline \multicolumn{4}{|l|}{ After the task } \\
\hline Anxiety rating & $0.30(0.54)$ & $0.17(0.51)$ & $0.21(0.49)$ \\
\hline Excitement rating & $1.04(0.98)$ & $1.0(0.77)$ & $0.86(0.99)$ \\
\hline Factor/interaction & $\mathrm{F} / \mathrm{t}$ & d.f. & $\mathrm{p}$ \\
\hline \multicolumn{4}{|c|}{ MANOVA on anxiety and excitement rating } \\
\hline Group & 0.76 & 4.140 & n.s. \\
\hline Time & 28.49 & 2.69 & 0.001 \\
\hline Group $\times$ time & 1.62 & 4.140 & n.s. \\
\hline \multicolumn{4}{|l|}{$\mathrm{t}$ test: before vs. after } \\
\hline Anxiety rating & -0.16 & 75 & n.s. \\
\hline Excitement rating & -2.94 & 75 & 0.01 \\
\hline
\end{tabular}

Figures in parentheses are standard deviations. the two main effects did not reach significance (group: $\mathrm{F}_{2,72}=0.25$, n.s.; interference type: $\mathrm{F}_{1,72}=2.52$, n.s.). Paired comparison between the panic and phobia interference index per group based on the variance $t$ test for dependent measures revealed a significantly higher interference index for phobia compared to the panic interference index $\left(t_{28}=-0.05, p<0.05\right.$, Cohen's $\left.d=0.35\right)$ only in the $\mathrm{CPHOB}$ group. Contrary to expectation, there was no significant effect in the CPAN group. Post hoc Student-Newman-Keuls tests for the panic and phobia interference index revealed no significant group differences for both interference indices. The sample size provided $80 \%$ power to detect a medium effect size (Cohen's $\mathrm{d}=$ $0.50)$.

To test gender differences in the Stroop task, we conducted separate $t$ tests for each group on interference index scores (panic, phobia) and on reading times for panic, spider phobia, and neutral word cards. In the $\mathrm{CPHOB}$ group, boys showed significantly longer reaction times for panic $\left(\mathrm{t}_{17}=-2.36, \mathrm{p}<0.05\right)$ and phobia cards $\left(\mathrm{t}_{4.29}=\right.$ $-2.85, \mathrm{p}<0.05)$ compared to girls. In the CCON group, boys showed a significantly higher panic interference score compared to girls $\left(\mathrm{t}_{27}=-3.23, \mathrm{p}<0.01\right)$. Highly significant correlations between age and reading times emerged for all word types (panic: $r=-0.68$, phobia: $r=$ -0.64 , neutral: $r=-0.67$ ), whereas no significant correlations were found between age and interference score index (panic: $r=0.17$, phobia: $r=-0.02$ ).

Attention Bias in Children of

Panic-Disordered Patients

\section{Anxiety and Excitement Rating}

Means, standard deviations, and detailed results of the statistical analyses on these variables are reported in table 3. A $3 \times 2$ MANOVA performed on anxiety rating and excitement rating revealed a significant time effect, but no significant group effect and no significant interaction. Subsequent paired $t$ tests for the whole sample indicated an increase only in excitement rating after baseline $\left(\mathrm{t}_{75}=-2.94, \mathrm{p}<0.01\right)$.

\section{Exploratory Analyses}

To examine whether reactions to the experimental task were influenced by the diagnostic status of the children, additional analyses were performed comparing two groups: children with a primary diagnosis of anxiety disorder $(\mathrm{n}=32)$ and children without a history of any psychiatric diagnoses $(n=40)$. Since there were only 3 children with a primary diagnosis other than anxiety disorders, we excluded these children from this analysis. A 3 $\times 2$ ANOVA with the factors group and interference type performed on interference index scores revealed no significant group $\times$ interference type interaction.

To test whether the groups differ in general in interference susceptibility, we analyzed color-naming times for color words. A one-way ANOVA revealed no significant group factor $\left(\mathrm{F}_{2.71}=0.72\right.$, n.s. $)$. Also the analyses of error rates (mistakes in articulations and color naming) revealed no group differences.

Psychopathology 2008;41:179-186 


\section{Discussion}

Our results did not confirm the hypothesis that children of panic patients show an attention bias for panicrelevant stimuli. We did not find a higher interference index score with panic-relevant words than phobia-relevant words in children of parents with panic disorder and these children did not show a higher interference score for the panic interference index compared to children of individuals with animal phobia and children of healthy controls. These findings are consistent with the results of Schwartz et al. [24] and Kagan et al. [25], but in contrast to the findings of the study of Ehlers et al. [6] and Stewart et al. [23]. It should be noted that in this study as well as in the study of Schwartz et al. [24] and Kagan et al. [25] children were investigated whereas the studies of Ehlers et al. [6] and Stewart et al. [23] investigated adults. The question arises whether the inconsistent results between these studies are a consequence of the different ages in the samples. However, investigations by Martin et al. [15, 43] and Vasey [40] indicated that Stroop interference effects can be shown even in children as young as age $4-5$, and 6, respectively. However, Kindt et al. [20] found that a bias for spider words is a normal characteristic in children aged 8 , and that at the age of 11 cognitive bias starts to differentiate between fearful and nonfearful children. Nevertheless, the results of our study cannot be fully explained as a consequence of the age of the participants.

The group of children of individuals with spider phobia showed a higher interference score with spider phobia-relevant words than with panic-relevant words. But again, we found no group differences for the spider phobia interference index.

Since a substantial number of children of panic patients had anxiety diagnoses and in particular $32 \%$ of children of individuals with animal phobia, $15 \%$ of children of individuals with panic disorder and $0 \%$ of children of healthy controls already had a spider phobia, the question arises whether the interference effect with spider phobia-related words is an expression of the diagnostic status of these children. In an additional analysis, children were grouped according to their own diagnosis. The comparison between children with a primary diagnosis of anxiety disorder and children without a history of any psychiatric diagnoses revealed no significantly different group effects in the Stroop task. However, a strong test of the effect of the spider phobia diagnosis in the children on attentional bias needs to compare the children with spider phobia in the $\mathrm{CPHOB}$ group with the children without spider phobia in the $\mathrm{CPHOB}$ group. Because of the small number of children with spider phobia $(n=6)$, we were not able to complete this analysis. However, the means of phobia interference scores of the children with spider phobia was higher than the scores of the children without that diagnosis. Therefore, the observed attention bias towards spider phobia-relevant words may represent an expression of the diagnostic status of the child rather than a possible precursor of anxiety disorder. Moreover, the above-mentioned findings in the children of panic patients seem to be more strongly associated with their parents' symptomatology than with their own diagnostic status.

Interestingly, in another study we compared once again children of individuals with panic disorder, children of individuals with animal phobia, and children of normal controls with respect to their interpretations of ambiguous scenarios, which included three types of stimuli: panic-relevant, animal phobia-relevant, and panic-irrelevant stimuli [44]. The results of this investigation indicated that children of individuals with panic disorder reported interpretation bias with respect to panic-relevant symptoms, but this bias could only be observed after priming with a panic model. Interestingly, these children showed an interpretation bias in the absence of panic attacks.

With the above results in mind, the question arises why no attention bias towards panic-relevant stimuli was found in children of individuals with panic disorder. One explanation could be that, like in the study of Schneider et al. [44], the children need to be primed. However, this hypothesis needs to be tested in another study. Gotlib et al. [45] investigated children of bipolar patients. After a negative mood induction and the administration of an emotional Stroop test, children of parents with bipolar disorder were found to exhibit an attentional bias towards social-threat-related and manic-irritable words. An explanation offered by Mathews [46] emphasizes that current theoretical models of cognitive biases in anxiety accept that an event must first be appraised as a potential threat before it preferentially attracts attention. Thus, the interpretation of the meaning of an event seems to be primary although attentional processes may subsequently play a role in maintaining the awareness of that meaning. This assumption indicates that in the etiology of panic disorder as well as anxiety disorders, the existence of an interpretation bias could be the first step in the development of such disorders, which will be followed by attention bias. In this case, attention bias can be measured soon after the development of an anxiety disorder or a component of anxiety disorders but not before, whereas 
interpretation bias can be measured before the anxiety disorder or components of the disorder have been established. The pattern of results of this investigation as well as the results of the study of Schneider et al. [44] support this assumption. We found interpretation bias and no attention bias in children at risk for developing panic disorder, who had never experienced a panic attack.

A relation between spider fear and bias was observed when age was taken into account: bias for spider-related words decreased with age in nonfearful children, whereas this bias remained in the fearful group $[19,20]$. However, before generalizing these results, further studies are needed that replicate these findings and clarify the question whether attention bias can be observed after priming. In accordance with these findings, it also has to be considered that it might not primarily be a cognitive process, such as the attentional bias, which causes panic, but a complex emotional process in which cognitive processes may play a secondary role. In summary, the question regarding the origin of the development of panic cannot currently be resolved.

The findings of sex differences are puzzling. So far, no study reported sex differences in the Stroop task. A possible explanation may be the unequally distributed sample size in the $\mathrm{CPHOB}$ group.

A limitation of the present study is the composition of the animal phobia group, which includes a variety of animals. However, a strong test of the influence of a spider phobia parent on the Stroop interference effect in their children needs to have a group of parents all of whom suf- fer from spider phobia. A further limitation of this investigation is the use of a stopwatch to measure the speed of reading.

Negative findings may also reflect problems inherent in the Stroop paradigm and contrasting results can alternatively be attributed to variations in procedural detail [47]. It will be essential to evaluate the psychometric properties of the emotional Stroop task itself. Furthermore, it has to be questioned whether the used panic-relevant words have the same meaning for children and for adults. Words like death or emergency doctor may stimulate different cognitive processes in children than in adults. However, in a pilot study, we could show that children of the same age group rated the panic-relevant words as more threatening than the used neutral words.

Finally, our results need to be replicated, using an emotional Stroop task with a priming manipulation. At present, with the results of this investigation and other Stroop studies in mind, it cannot be concluded whether an attentional bias exists in children at risk for anxiety disorders or whether the Stroop task itself is the correct method of choice in assessing the attentional bias.

\section{Acknowledgments}

The preparation of this paper was supported by the German Research Foundation (DFG) grants Ma 1116/1-1, Ma 1116/1-4 and by the Christoph Dornier Foundation for Clinical Psychology, Marburg Institute.

\section{References}

1 Williams JMG, Watts FN, MacLeod C, Mathews A: Cognitive Psychology and Emotional Disorders, ed 2. Chichester, Wiley, 1997.

2 Barlow DH: Anxiety and Its Disorders, ed 2. New York, Guilford Press, 2002.

3 Beck AT, Emery G, Greenberg RL: Anxiety Disorder and Phobias: A Cognitive Perspective. New York, Basic Books, 1985.

4 Ehlers A, Margraf J: The psychophysiological model of panic; in Emmelkamp PMG, Everead W, Kraaymaat F, Van Son M (eds): Fresh Perspectives on Anxiety Disorders. Amsterdam, Swets \& Zeitlinger, 1989, pp 129.

5 Margraf J, Ehlers A: Etiological model of panic - psychophysiological and cognitive aspects; in Baker R (ed): Panic Disorder: Research and Therapy. London, Wiley, 1989, pp 205-231.

\footnotetext{
6 Ehlers A, Margraf J, Davies S, Roth WT: Selective processing of threat cues in subjects with panic attacks. Cogn Emot 1988;2:201219.

7 Lundh LG, Wikström J, Westerlund J, Öst LG: Preattentive bias for emotional information in panic disorder with agoraphobia. J Abnorm Psychol 1999;108:222-232.

8 McNally RJ, Litz BT, Prassas A: Emotional priming of autobiographical memory in post-traumatic stress disorder. Cogn Emot 1994;8:351-367.

9 McNally RJ, Riemann BC, Kim E: Selective processing of threat cues in panic disorder. Bev Res Ther 1990;28:407-412.

10 Maier W, Buller R, Hallmayer J: Comorbidity of panic disorder and major depression: results from a family study; in Hand I, Wittchen HU (eds): Panic and Phobias. Berlin, Springer, 1988, pp 180-185.
}

11 Weissman MM, Wickramaratne P, Adams PB, Lish JD, Horwath E, Charney D, Woods SW, Leeman E, Frosch E: The relationship between panic disorder and major depression: a new family study. Arch Gen Psychiatry 1993;50:767-780.

12 Biederman J, Faraone SV, Hirshfeld-Becker DR, Friedman D, Robin JA, Rosenbaum JF: Patterns of psychopathology and dysfunction in high-risk children of parents with panic disorder and major depression. Am J Psychiatry 2001;158:49-57.

13 Eley TC: Contributions of behavioral genetics research: quantifying genetic, shared environmental and nonshared environmental influences; in Vasey MW, Dadds MR (eds): The Developmental Psychopathology of Anxiety. Oxford, University Press, 2001, pp 45-59. 
14 Moradi A, Taghavi R, Neshat-Doost H, Yule W, Dalgleish T: The performance of children and adolescents with PTSD on the Stroop colour naming task. Psychol Med 1999;29:415419.

15 Martin M, Jones GV: Integral bias in the cognitive processing of emotionally linked pictures. Br J Psychol 1995;86:419-435.

-16 Taghavi MR, Dalgleish T, Moradi AR, Neshat-Doost HT, Yule W: Selective processing of negative emotional information in children and adolescents with generalized anxiety disorder. Br J Clin Psychol 2003;42:221230.

17 Dalgeish T: Performance on the emotional Stroop task in groups of anxious, expert, and control subjects: a comparison of computer and card presentation formats. Cogn Emot 1995;9:341-362.

18 Morren M, Kindt M, van den Hout M, van Kasteren H: Anxiety and the processing of threat in children: further examination of the cognitive inhibition hypothesis. Behav Change 2003;20:131-142.

$\checkmark 19$ Kindt M, Bierman D, Brosschot JF: Cognitive bias in spider fear and control children: assessment of emotional interference by a card format and a single-trial format of the Stroop task. J Exp Child Psychol 1997;66: 163-179.

20 Kindt M, Van Den Hout M, De Jong P, Hoekzema B: Cognitive bias for pictorial and linguistic threat cues in children. J Psychopathol Behav Assess 2000;22:201-219.

21 Reed V, Wittchen HU: DSM-IV panic attacks and panic disorder in a community sample of adolescents and young adults: how specific are panic attacks? J Psychiatr Res 1998:32:335-345.

22 Goodwin RD, Gotlib IH: Panic attacks and psychopathology among youth. Acta Psychiatr Scand 2004; 109:216-221.

-23 Stewart SH, Conrod PJ, Gignac ML, Pihl RO: Selective processing biases in anxiety-sensitive men and women. Cogn Emot 1998;12: 105-133.

-24 Schwartz CE, Snidman N, Kagan J: Early temperamental predictors of Stroop interference to threatening information at adolescence. J Anxiety Disord 1996;10:89-96.
25 Kagan J, Snidman N, Zentner M, Peterson E: Infant temperament and anxious symptoms in school age children. Dev Psychopathol 1999;11:209-224.

-26 Fyer AJ, Mannuzza S, Gallops MS, Martin LY, Aaronson C, Gorman JM: Familial transmission of simple phobias and fears. Arch Gen Psychiatry 1990;47:252-256.

27 Fyer AJ, Mannuzza S, Chapman TF, Martin LY, Klein DF: Specificity in familial aggregation of phobic disorders. Arch Gen Psychiatry 1995;52:564-573.

28 Lipsitz JD, Barlow DH, Mannuzza S, Hofmann SG, Fyer AJ: Clinical features of four DSM-IV-specific phobia subtypes. J Nerv Ment Dis 2002;190:471-478.

29 Margraf J, Schneider S, Ehlers A: Diagnostisches Interview bei psychischen Störungen (DIPS). Interviewleitfaden. Berlin, Springer, 1994.

30 Di Nardo PA, Brown TA, Barlow DH: Anxiety Disorders Interview Schedule for DSMIV Lifetime (ADIS-IV-L). New York, Graywind Publications Incorporated, 1994.

31 American Psychiatric Association: Diagnostic and Statistical Manual of Mental Disorders, ed 4 revised. Washington, American Psychiatric Association, 1994.

32 Keller A: Die Klassifikation psychischer Störungen nach DSM-IV mit Hilfe eines strukturierten diagnostischen Interviews (F-DIPS); unpubl. Dissertation, RuprechtKarls-Universität Heidelberg, 2000.

33 Ollendick TH, Mattis SG, King NJ: Panic in children and adolescents: a review. J Child Psychol Psychiatry 1994;35:113-134.

34 Spielberger CD, Gorsuch RL, Lushenek RE: Manual for the State-Trait Anxiety Inventory (Self-Evaluation Questionnaire). Palo Alto, Consulting Psychologists Press, 1970.

35 Unnewehr S, Schneider S, Margraf J: Das State-Trait-Angstinventar für Kinder (STAIK) - German translation of the StateTrait-Anxiety Inventory for Children (STAIC). Unpubl. manuscript, PhilippsUniversität Marburg, 1990
36 Margraf J: Beiträge zur Diagnostik: Theorie und Therapie des Paniksyndroms; unpubl. Habilitationsschrift, Philipps-Universität Marburg, 1989.

37 Unnewehr S, Schneider S, Margraf J: Diagnostisches Interview bei psychischen Störungen im Kindes- und Jugendalter (KinderDIPS). Berlin, Springer, 1995.

38 Schneider S, Unnewehr S, Margraf J: KinderDIPS. Berlin, Springer, 1995

39 Unnewehr S, Schneider S, Florin I, Margraf J: Psychopathology in children of patients with panic disorder or animal phobia. Psychopathology 1998;31:69-84.

-40 Vasey MW: Anxiety-related attentional biases in childhood. Behav Change 1996;13: 199-205.

41 Waters AJ, Sayette MA, Franken IHA, Schwartz JE: Generalizability of carry-over effects in the emotional Stroop task. Bev Res Ther 2005;43:715-732.

42 Elting DT, Hope DA: Cognitive assessment; in Heimberg RG, Liebowitz MR (eds): Social Phobia: Diagnosis, Assessment, and Treatment. New York, Guilford Press, 1995, pp 232-258.

43 Martin M, Horder P, Jones GV: Integral bias in naming of phobia-related words. Cogn Emot 1992;6:479-486.

44 Schneider S, Unnewehr S, Florin I, Margraf J: Priming panic interpretations in children of patients with panic disorder. J Anxiety Disord 2002;16:605-624.

45 Gotlib IA, Traill SK, Montoya RL, Joormann J, Chang K: Attention and memory biases in the offspring of parents with bipolar disorder: indications from a pilot study. J Child Psychol Psychiatry 2005;46:84-93.

46 Mathews A: Information-processing biases in emotional disorders; in Clark DM, Fairburn CG (eds): Science and Practice of Cognitive Behaviour Therapy. London, Oxford University Press, Oxford Medical Publications, 1997, pp 47-66.

47 Vasey MW, MacLeod C: Information-processing factors in childhood anxiety: a review and developmental perspective; in Vasey MW, Dadds MR (eds): The Developmental Psychopathology of Anxiety. Oxford, University Press, 2001, pp 253-277. 